\title{
The Activity of Serum 8-Iso-Prostaglandin F2 $\alpha$ as Oxidative Stress Marker in Patients with Diabetes Mellitus Type 2 and Associated Dyslipidemic Hyperglycemia
}

\author{
Mohammed H. Mukhtar'1, Hoda M. El-Emshaty ${ }^{2 *}$, Hiba S. Alamodi' ${ }^{1}$, Wesam A. Nasif1,3* \\ ${ }^{1}$ Biochemistry Department, Faculty of Medicine, Umm Al-Qura University, Makkah, Saudi Arabia \\ ${ }^{2}$ Gastroenterology Center, Faculty of Medicine, Mansoura University, Mansoura, Egypt \\ ${ }^{3}$ Molecular Biology Department, Genetic Engineering and Biotechnology Research Institute, \\ Sadat City University, Sadat City, Cairo, Egypt \\ Email: *elemshaty_h@yahoo.com, *wnasif2003@yahoo.com, *wanasif@uqu.edue.sa, \\ mhmukhtar@uqu.edu.sa, hsamodi@uqu.edu.sa,Alamodi@hotmail.co.uk
}

How to cite this paper: Mukhtar, M.H., El-Emshaty, H.M., Alamodi, H.S. and Nasif, W.A. (2016) The Activity of Serum 8-Iso-Prostaglandin F2 $\alpha$ as Oxidative Stress Marker in Patients with Diabetes Mellitus Type 2 and Associated Dyslipidemic Hyperglycemia. Journal of Diabetes Mellitus, 6, 318-332. http://dx.doi.org/10.4236/jdm.2016.64033

Received: November 7, 2016

Accepted: November 26, 2016

Published: November 29, 2016

Copyright $\odot 2016$ by authors and Scientific Research Publishing Inc. This work is licensed under the Creative Commons Attribution International License (CC BY 4.0).

http://creativecommons.org/licenses/by/4.0/

(c) (i) Open Access

\section{Abstract}

Background: Oxidative stress has been closely linked to the incidence of diabetic complications. Therefore, the aim of this research article was to study hyperglycemia and abnormal lipid profile in diabetic patient type 2 and its correlation with oxidative stress development as measured by 8 -iso-PGF2 $\alpha$ and 8 -OHdG. Methods: Fifty (50) patients confirmed type 2 diabetes mellitus and eighty (80) non-diabetic control individuals were included in this study. All individuals were tested for blood glucose, lipid profile, 8 -iso-PGF2 $\alpha$ and 8 -OHdG HdG. Results: The age of diabetic patients was observed to be $\geq 40$ yrs in $96 \%$ and diabetes was frequently detected in female than in male patients $(76 \%$ vs. $24 \%$, p < 0.0001$)$. Mean serum lipids were elevated in diabetic patients compared with control individuals ( $\mathrm{p}<0.0001$ ) except in HDL-C, a significant decrease was recorded $(\mathrm{p}=0.04)$. Serum 8 -iso-PGF2 $\alpha$ and 8 -OHdG were elevated significantly in diabetic patients compared with non-diabetic control and a significant correlation was recorded between them $(\mathrm{r}=0.6, \mathrm{p}<0.0001)$. 8-iso-PGF2 $\alpha$ was associated with Age $(\mathrm{r}=0.394, \mathrm{p}<0.0001)$, FBG $(0.553, \mathrm{p}<0.0001)$, LDL-C $(\mathrm{r}=$ $0.2, \mathrm{p}=0.023)$, TG $(\mathrm{r}=0.176, \mathrm{p}=0.045)$ and $\mathrm{TC}(\mathrm{r}=0.2, \mathrm{p}=0.02)$. Also, 8-OHdG was associated with age $(r=0.558, p<0.0001)$, FBG $(r=0.67, p<0.0001)$, LDL-C $(r$ $=0.28, \mathrm{p}=0.001)$, TG $(\mathrm{r}=0.358, \mathrm{p}<0.0001)$ and TC $(\mathrm{r}=0.33, \mathrm{p}<0.0001)$. Age, FBG, HbA1c, LDL-C, TG and TC showed a significant linear regression with 8-isoPGF2 $\alpha$ and $8-\mathrm{OHdG}$ recording its role as significant predictors for the elevation of 8-iso-PGF2 $\alpha$ and 8-OHdG. Therefore, hyperglycemia with oxidative stress development may play a role for dyslipidemia and diabetic complications. Conclusion: Di- 
abetic patient's type 2 has a higher rate of abnormal serum lipids and correlates significantly with lipid peroxidation and oxidized DNA bases as measured by 8 -isoPGF $2 \alpha$ and 8 -OHdG. Therefore, 8 -iso-PGF $2 \alpha$ and 8-OHdG could be used as oxidative biomarkers for evaluating diabetic patients with early prediction of its complications and cancer development.

\section{Keywords}

Diabetes Mellitus Type 2, 8-iso-PGF2 $\alpha$, 8-OHdG, ELISA, Abnormal Lipid Profile

\section{Introduction}

Diabetes mellitus is a group of metabolic diseases characterized by hyperglycemia resulting from defects in insulin secretion and insulin action or both [1]. In type 2 diabetes, the cause is a combination of resistance to insulin action and an inadequate compensatory insulin secretory response.

Insulin resistance and type 2 diabetes are associated with a clustering of interrelated plasma lipid and lipoprotein abnormalities, which include reduced HDL cholesterol, a predominance of small dense LDL particles, and elevated triglyceride levels. Each of these dyslipidemic features is associated with an increased risk of cardiovascular disease [2]. Insulin resistance has striking effects on lipoprotein size and subclass particle concentrations for VLDL, LDL and HDL [3] [4].

Oxidative stress due to overproduction of reactive oxygen species (ROS) has important role in prevention, initiation, and progression of chronic diseases from early childhood [5]. The considerable reactive properties of ROS cause oxidative damage to lipids, deoxyribonucleic acid (DNA), and proteins. Recent evidence suggests that ROS could have a role in the development of hypertension, dyslipidemia, diabetes mellitus, and atherosclerosis [6]. Oxidative stress status in diabetes could be clearly demonstrated by the increase of some specific biomarkers such as lipid hydroperoxides, DNA adducts and protein carbonyls [7].

Reactive oxygen species (ROS) can interact with DNA to produce damage including single- and double-stranded DNA breaks, deletions and nucleoside modifications. Among purine and pyrimidine base, guanine is more susceptible to oxidation. The hydroxyl radical can attack to C-8 position guanine and generate an oxidation product, 8-hydroxy deoxyguanine (8-OHdG) [8]. 8-OHdG, the oxidized form of the nucleoside 2'-deoxyguanosine present in DNA, is one of the most reliable and abundant markers of DNA damage because it reflects generalized cellular oxidative stress; it may be a risk factor for cancer, atherosclerosis and DM [6] [8].

Lipid peroxidation is most often measured using malondialdehyde (MDA) and 8-isoprostaglandin F2 $\alpha$ (8-iso-PGF2 $\alpha$ ) [9] [10] [11]. Isoprostanes are stable products of arachidonic acid peroxidation due to free radical activity and reliable biomarkers for oxidative stress, which are suitable for measuring lipid peroxidation in place of malondialdehyde (MDA) [12]. Isoprostanes, including 8-iso-PGF2 $\alpha$ are stable in biological fluids 
and easily detectable as well as not being affected by diet and modulated by endogenous antioxidants [13].

The measurement of bioactive F2-IsoPs levels offers a unique noninvasive analytical tool to study the role of free radicals in physiology, oxidative stress-related diseases, and acute or chronic inflammatory conditions [14]. Elevated F2-IsoP levels have been associated with multiple chronic conditions which commonly have been interpreted as an etiological link between oxidative stress and the disease; specifically, type 2 diabetes and its risk factors, such as obesity, impaired glucose tolerance, and insulin resistance [15]. Therefore, the objective of this research article was to study hyperglycemia and abnormal lipid profile in diabetic patients and its correlation with oxidative stress development as detected by 8 -iso-PGF $2 \alpha$ and 8 -OHdG.

\section{Subjects and Methods}

\subsection{Subjects}

Fifty (50) patients confirmed type-2 diabetes mellitus (12 males and 38 females; mean age $51.04 \pm 7.49$ yrs) and eighty (80) non-diabetic control individuals (52 males and 28 females; mean age $39.7 \pm 10.1 \mathrm{yrs}$ ) were included in this study. This study was done in collaboration between biochemistry department, faculty of medicine, Umm Al-Qura University, Makkah Al-Mukarama, Kingdom of Saudi Arabia and Gastroenterology surgical center, Mansoura University, Mansoura, Egypt from 2014-2016. The study protocol was approved by Ethics Review Board for Human Studies at Faculty of Medicine, Umm Al-Qura University and conformed to the ethical guidelines of the 1975 Helsinki declaration.

All participants underwent a clinical examination and a questionnaire including medical and family history. The exclusion criteria were for those with past history of type-1 diabetes, cancer, cardiovascular or renal diseases. Blood samples were obtained following at least 8 hours fasting period according to the American Diabetes Association criteria; only patients with fasting blood glucose above $126 \mathrm{mg} / \mathrm{dl}$ or postprandial two hours after meal above $200 \mathrm{mg} / \mathrm{dl}$ were included [16]. Blood samples were collected for blood glucose analysis and serum was immediately separated by centrifugation at $3000 \mathrm{rpm}$ for $10 \mathrm{~min}$ and stored at $4^{\circ} \mathrm{C}$ until processed for lipid analysis and oxidative biomarkers (8-OHdG and 8-iso-PGF2 $\alpha$ ).

\subsection{Measurement of Biochemical Parameters}

Fasting blood sugar (FBS), postprandial blood sugar (PBS), Triglycerides (TG), total cholesterol (TC) and high density lipoprotein-cholesterol (HDL-C) were measured with an autoanalizer (COBAS INTEGRA 400PLUS, Roche, Germany) using commercial kits. Serum LDL-C was calculated according to the computational formula of Friedewald et al. [17] [LDL = TC-HDL-TC/5.0 mg/dl]. Castelli index [18] was used for determining the ratio between total cholesterol and HDL-C.

Dyslipidemia (Abnormal lipid profile) was defined using the National cholesterol Education program Adult treatment panel III (NCEP-ATP III) [19]. In addition, he- 
moglobinA1c (HbA1c \%) was measured according to DCCT (Diabetes Control and Complications Trial) [20].

\subsection{Serum 8-Iso-PGF2 $\alpha$}

8-iso-PGF2 $\alpha$ was measured by direct 8-iso-PGF2 $\alpha$ ELISA kit (Enzo Iife Sciences Inc., Switzerland). The direct 8 -iso-PGF2 $\alpha$ ELISA kit is a competitive immunoassay for the quantitative determination of 8 -iso-PGF2 $\alpha$ in biological fluids [21]. The kit uses a polyclonal antibody to 8 -iso-PGF2 $\alpha$ to bind in a competitive manner with 8 -iso-PGF2 $\alpha$ in the sample or 8 -iso-PGF2 $\alpha$ covalently attached to alkaline phosphatase. After incubation, the excess reagents were washed away and substrate was added. The generated yellow color was read at $405 \mathrm{~nm}$ and the intensity of the bound yellow color is inversely proportional to the concentration of 8 -iso-PGF $2 \alpha$ in either standard or sample. The measured optical density is used to calculate the concentration of 8 -iso-PGF $2 \alpha$ from the calibration curve.

\subsection{Serum 8-0HdG}

Serum 8-OHdG was measured using an ELISA kit (Cloud-clone Corp., Assembled by USCo life science inc. USA). This assay employs the competitive inhibition enzyme immunoassay technique. Pre-coated microplate with $8-\mathrm{OHdG}$ monoclonal antibody used for competitive inhibition reaction between biotin-labeled 8-OHdG and unlabeled 8-OHdG. After incubation, the unbound conjugate is washed off with subsequent addition of avidin conjugated horse radish peroxidase (HRP) followed by substrate solution. The intensity of the developed color is reversely proportional to the concentration of $8-\mathrm{OHdG}$ in the sample. The detection range was from 74.07 to $6,000 \mathrm{pg} / \mathrm{ml}$.

\subsection{Statistical Analysis}

Data was analyzed using SPSS (version 17, Sydney, NSW, Australia). Statistical analysis was performed using independent sample test for parametric variables and Chi-square for categorical variables. Relationship between variables was detected by Pearson's correlation coefficient and linear regression analysis was performed to analyze 8-OHdG and 8-iso-PGF2 $\alpha$ as dependent variables. Quantitative data was expressed as mean \pm SD and qualitative data as frequencies and percentages.

\section{Results}

General characteristics and biochemical markers of the study group were listed in Table 1. Diabetic patients were aged < 40 yrs in 4\%, 40 - 49 yrs in 42\%, 50 - 59 yrs in $42 \%$ and $\geq 60$ yrs in $12 \%$. Diabetes was more frequently detected in female than in male patients $(76 \%$ vs. $24 \%, \mathrm{p}<0.0001)$. Hyperglycemia as measured by FBG, PPG and HbA1c showed significant elevation in diabetic patients compared to non-diabetic control $(184.4 \pm 56.9 \mathrm{mg} / \mathrm{dl}, 328.1 \pm 75.7 \mathrm{mg} / \mathrm{dl}, 7.06 \pm 0.7 \%$ vs. $80.97 \pm 6.78 \mathrm{mg} / \mathrm{dl}, 97.78 \pm$ $10.1 \mathrm{mg} / \mathrm{dl}, 3.7 \pm 0.6 \%$ respectively, $\mathrm{p}<0.0001)$.

Mean serum lipids showed significant elevation in diabetic patients compared to 
Table 1. General characteristics and biochemical markers of all participants in the study group.

\begin{tabular}{cccc}
\hline Variable & $\begin{array}{c}\text { Diabetic Patients } \\
(\mathrm{n}=50)\end{array}$ & $\begin{array}{c}\text { Non-Diabetic Control } \\
(\mathrm{n}=80)\end{array}$ & p value* \\
\hline Sex & $38 / 12$ & $28 / 52$ & $<0.0001$ \\
F & $38(76 \%)$ & $28(35 \%)$ & \\
M & $12(24 \%)$ & $52(65 \%)$ & \\
Age $(\mathrm{yrs})$ & $51.04 \pm 7.49$ & $39.7 \pm 10.1$ & \\
$<40$ & $2(4 \%)$ & $46(57.5 \%)$ & \\
$40-49$ & $21(42 \%)$ & $19(23.75 \%)$ & $<0.0001$ \\
$50-59$ & $21(42 \%)$ & $13(16.25 \%)$ & $<0.0001$ \\
$\geq 60$ & $6(12 \%)$ & $2(2.5 \%)$ & $<0.0001$ \\
FBG $(\mathrm{mg} / \mathrm{dl})$ & $184.4 \pm 56.9$ & $80.97 \pm 6.78$ & \\
PPG (mg/dl) & $328.1 \pm 75.7$ & $97.78 \pm 10.1$ & $<0.0001$ \\
HbA1c $(\%)$ & $7.06 \pm 0.7$ & $3.7 \pm 0.6$ & $<0.0001$ \\
Lipid profile $(\mathrm{mg} / \mathrm{dl})$ & & & 0.04 \\
TG & $142.4 \pm 63.6$ & $98.4 \pm 37.58$ & $<0.0001$ \\
TC & $222.6 \pm 37.87$ & $193.4 \pm 22.27$ & 0.001 \\
HDL-C & $48.84 \pm 9.49$ & $52.5 \pm 10.15$ & \\
LDL-C & $144.56 \pm 34.8$ & $120.8 \pm 18.6$ & \\
TC/HDL-C & $4.7 \pm 1.2$ & $3.8 \pm 0.6$ & \\
\hline
\end{tabular}

${ }^{*} \mathrm{p}$ value is significant $<0.05$; Abbreviations: FBG (Fasting blood glucose), HbAlc (Glycated hemoglobin), LDL-C (Low density lipoprotein-cholesterol), HDL-C (High density lipoprotein-cholesterol), TG (Triglycerides), TC (Total cholesterol).

non-diabetic control individuals except in HDL-C a significant decrease was recorded (Table 1). LDL-C, TG and TC were elevated significantly in diabetic patients compared to non-diabetic control $(144.56 \pm 34.8,142.4 \pm 63.6,222.6 \pm 37.87 \mathrm{mg} / \mathrm{dl}$ vs. $120.8 \pm$ 18.6, $98.4 \pm 37.58,193.4 \pm 22.27 \mathrm{mg} / \mathrm{dl}$ respectively, $\mathrm{p}<0.0001)$. TC/HDL-C showed also significant elevation in diabetic patients compared to non-diabetic control (4.7 \pm 1.2 vs. $3.8 \pm 0.6 \mathrm{mg} / \mathrm{dl}, \mathrm{p}=0.001)$ but in HDL-C, a significant decrease was recorded $(48.84 \pm 9.49$ vs. $52.5 \pm 10.15 \mathrm{mg} / \mathrm{dl}, \mathrm{p}=0.04)$.

Abnormal serum lipids was recorded in diabetic patients with a significant difference compared to non-diabetic control as regard to LDL-C (56\% vs. $28.8 \%, \mathrm{p}=0.002)$, TG ( $28 \%$ vs. $5 \%, \mathrm{p}<0.0001)$, TC ( $76 \%$ vs. $38.8 \%, \mathrm{p}<0.0001)$ and TC/HDL-C $(68 \%$ vs. $46.3 \%, \mathrm{p}=0.015)$ but the difference in abnormal HDL-C (60\% vs. $56.3 \%, \mathrm{p}=0.7)$ was not significant (Table 2).

Hyperglycemia as measured by FBG and $\mathrm{HbAlc}$ was correlated significantly with serum lipids (Figure 1). FBG showed a significant positive correlation with LDL-C ( $r=$ $0.411, \mathrm{p}<0.0001)$ and TG $(\mathrm{r}=0.32, \mathrm{p}<0.0001)$. HbAlc showed a significant positive correlation with LDL-C $(r=0.409, \mathrm{p}<0.0001)$ and TG $(\mathrm{r}=0.401, \mathrm{p}<0.0001)$ but with HDL-C, a significant negative correlation was recorded $(\mathrm{r}=-0.17, \mathrm{p}=0.05)$.

Oxidative stress biomarkers 8-iso-PGF2 $\alpha$ and 8-OHdG in the sera of diabetic patients and control individuals were listed in Table 3 . Diabetic patients showed significant elevation of serum 8-iso-PGF2 $\alpha(2719.38 \pm 1864.68$ vs. $951.45 \pm 669.44 \mathrm{pg} / \mathrm{ml}, \mathrm{p}<$ $0.0001)$ and $8-\mathrm{OHdG}(178.35 \pm 26.23$ vs. $110.2 \pm 31.46 \mathrm{pg} / \mathrm{ml}, \mathrm{p}<0.0001)$ compared to 
Table 2. Abnormal serum lipids among all participants in the study group.

\begin{tabular}{cccccc}
\hline \multirow{2}{*}{ Group variable } & \multicolumn{5}{c}{ Abnormal lipid profile $^{+}$} \\
\cline { 2 - 6 } & LDL-C & HDL-C & TC & TG & TC/HDL-C \\
\hline Diabetic Patients $(\mathrm{n}=50)$ & $28(56 \%)$ & $30(60 \%)$ & $38(76 \%)$ & $14(28 \%)$ & $34(68 \%)$ \\
Non-Diabetic Control $(\mathrm{n}=80)$ & $23(28.8 \%)$ & $45(56.3 \%)$ & $31(38.8 \%)$ & $4(5 \%)$ & $37(46.3 \%)$ \\
p value & 0.002 & 0.7 & $<0.0001$ & $<0.0001$ & 0.015 \\
\hline
\end{tabular}

${ }^{*} \mathrm{p}$ value is significant $<0.05 ;{ }^{+}$Abnormal lipid profile was defined using the National Cholesterol Education Program Adult Treatment Panel III (NCEP-ATP III) [19]. Abbreviations: LDL-C (Low density lipoprotein-cholesterol), HDL-C (High density lipoprotein-cholesterol), TC (Total cholesterol), TG (Triglycerides).

Table 3. Incidence of 8-iso-PGF2 $\alpha$ and 8-OHdG in all participants of the study group.

\begin{tabular}{cccc}
\hline Variable & Diabetic Patients $(\mathrm{n}=50)$ & Non-Diabetic Control $(\mathrm{n}=80)$ & p value $^{*}$ \\
\hline 8-OHdG $(\mathrm{pg} / \mathrm{ml})$ & $178.35 \pm 26.23$ & $110.2 \pm 31.46$ & $<0.0001$ \\
8 -iso-PGF2 $\alpha(\mathrm{pg} / \mathrm{ml})$ & $2719.38 \pm 1864.68$ & $951.45 \pm 669.44$ & $<0.0001$ \\
\hline
\end{tabular}

${ }^{*} \mathrm{p}$ value is significant $<0.05 ; 8$-iso-PGF2 $\alpha$ (8-iso-prostaglandin F2 $\alpha$ ); 8-OHdG (8-hydroxy deoxyguanosin).
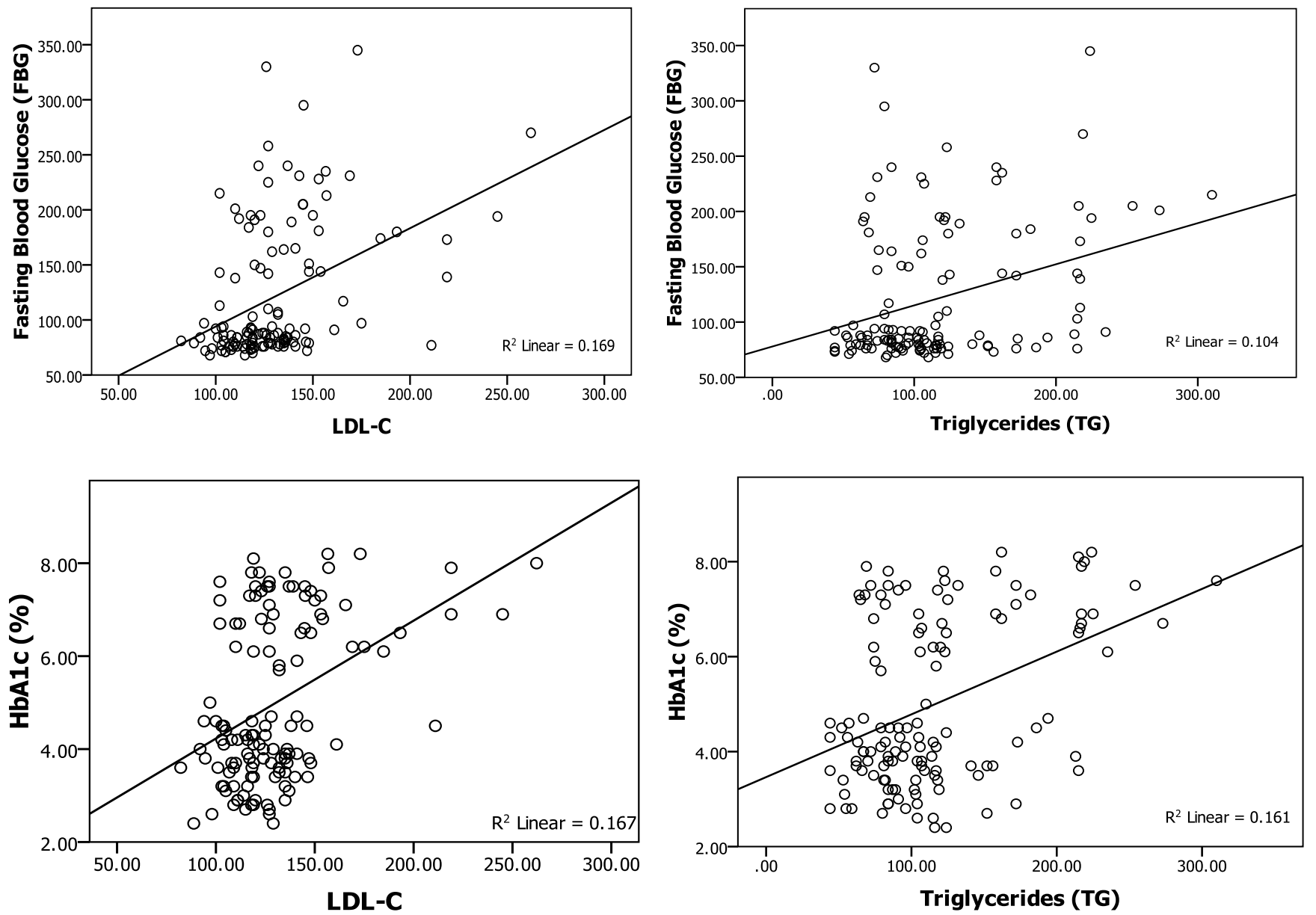

Figure 1. Correlation between Fasting blood glucose (FBG) and HbA1c with Low density lipoprotein-Cholesterol (LDL-C) and Triglyceride (TG) in all participants. 
control individuals. 8-iso-PGF2 $\alpha$ and 8-OHdG were associated significantly $(r=0.6, \mathrm{p}$ $<0.0001$ ) in all participants (Figure 2).

Pearson correlation of 8-OHdG and 8-iso-PGF2 $\alpha$ with age, hyperglycemia and lipid profile were recorded in Table 4. 8-iso-PGF2 $\alpha$ showed a significant positive correlation with Age $(\mathrm{r}=0.39, \mathrm{p}<0.0001)$, HbA1c $(\mathrm{r}=0.589, \mathrm{p}<0.0001)$, FBG $(0.55, \mathrm{p}<0.0001)$, LDL-C $(r=0.2, p=0.023)$, TG $(r=0.176, p=0.045)$ and TC $(r=0.2, p=0.02)$. Also, a significant positive correlation was detected between 8-OHdG and Age $(r=0.558, p<$ $0.0001)$, FBG $(\mathrm{r}=0.67, \mathrm{p}<0.0001)$, HbA1c $(\mathrm{r}=0.76, \mathrm{p}<0.0001)$, LDL-C $(\mathrm{r}=0.28, \mathrm{p}=$ $0.001)$, TG $(\mathrm{r}=0.36, \mathrm{p}<0.0001)$ and TC $(\mathrm{r}=0.33, \mathrm{p}<0.0001)$. However, with HDL, negative correlation was detected insignificant with both 8-OHdG and 8-iso-PGF2 $\alpha$.

Multiple linear regressions of 8-iso-PGF2 $\alpha$ and 8-OHdG with various independent variables (Table 5) showed that Age, FBG, HbA1c, LDL-C, TC and TG were recorded as significant predictors for the elevation of 8 -OHdG and 8 -iso-PGF2 $\alpha$.

Table 4. Pearson's correlation of 8-OHdG and 8-iso-PGF2 $\alpha$ with Age, FBG, HbA1c, and lipid profile.

\begin{tabular}{ccccccccc}
\hline & Age & FBG & HbA1c & LDL-C & HDL-C & TC & TG & TC/HDL-C \\
\hline \multirow{2}{*}{ 8-iso-PGF2 $\alpha$} & $0.394^{\mathrm{a}}$ & $0.553^{\mathrm{a}}$ & $0.589^{\mathrm{a}}$ & $0.20^{\mathrm{a}}$ & -0.107 & $0.203^{\mathrm{a}}$ & $0.176^{\mathrm{b}}$ & $0.233^{\mathrm{a}}$ \\
& 0.0001 & 0.0001 & 0.0001 & 0.023 & 0.226 & 0.021 & 0.045 & 0.008 \\
8-OHdG & $0.558^{\mathrm{a}}$ & $0.671^{\mathrm{a}}$ & $0.761^{\mathrm{a}}$ & $0.287^{\mathrm{a}}$ & -0.145 & $0.332^{\mathrm{a}}$ & $0.358^{\mathrm{a}}$ & $0.352^{\mathrm{a}}$ \\
& 0.0001 & 0.0001 & 0.0001 & 0.001 & 0.09 & 0.0001 & 0.0001 & 0.0001 \\
\hline
\end{tabular}

${ }^{\mathrm{a}}$ Correlation is significant at the 0.01 level (2tailed); ${ }^{\mathrm{b}}$ Correlation is significant at the 0.05 level (2tailed); Abbreviations: FBG (Fasting blood glucose), HbA1c (Glycated hemoglobin), LDL-C (Low density lipoprotein-cholesterol), HDL-C (High density lipoprotein-cholesterol), TC (Total cholesterol), TG (Triglycerides).

Table 5. Multiple linear regressions of 8-iso-PGF2 $\alpha$ and 8-OHdG with various independent variables.

\begin{tabular}{cccccccc}
\hline & Age & FBG & HbAlc & LDL-C & HDL-C & TG & TC \\
\hline 8-iso-PGF2 $\alpha$ & & & & & & \\
$\mathrm{R}$ & 0.39 & 0.55 & 0.589 & 0.2 & 0.107 & 0.176 & 0.203 \\
$\mathrm{R}^{2}$ & 0.155 & 0.306 & 0.347 & 0.04 & 0.01 & 0.03 & 0.04 \\
$\mathrm{P}^{*}$ & $<0.0001$ & $<0.0001$ & $<0.0001$ & 0.023 & 0.226 & 0.045 & 0.02 \\
$\mathrm{~B}^{\#}$ & 56.4 & 13.69 & $511 . .9$ & 10.76 & -16.3 & 5.03 & 9.56 \\
$(95 \%$ CI $)$ & $(33.4-79.4)(10.09-17.31)(389.1-634.7)(1.51-19.99)(-42.8-10.24)(0.11-9.95)$ & $(1.5-17.6)$ \\
8 -OhdG & & & & & & \\
$\mathrm{R}$ & 0.558 & 0.67 & 0.761 & 0.287 & 0.145 & 0.358 & 0.332 \\
$\mathrm{R}^{2}$ & 0.312 & 0.45 & 0.58 & 0.08 & 0.02 & 0.128 & 0.11 \\
$\mathrm{P}^{*}$ & $<0.0001$ & $<0.0001$ & $<0.0001$ & 0.001 & 0.09 & $<0.0001$ & $<0.0001$ \\
$\mathrm{~B}^{\#}$ & 2.32 & 0.48 & 19.21 & 0.449 & -0.64 & 0.297 & 0.46 \\
$(95 \% \mathrm{CI})$ & $(1.72-2.9)$ & $(0.39-0.58)$ & $(16.4-22.07)$ & $(0.19-0.71)$ & $(-1.4-0.123)$ & $(0.16-0.43)(0.23-0.68)$
\end{tabular}

${ }^{*} \mathrm{p}$ value is significant $<0.05$; ${ }^{*} \mathrm{~B}$ indicates standardized partial regression coefficient; Variables included: Age, FBG (Fasting blood glucose), HbA1c (Glycated hemoglobin), LDL-C (Low density lipoprotein), HDL-C (High density lipoprotein), TG (Triglycerides), TC (Total cholesterol). 


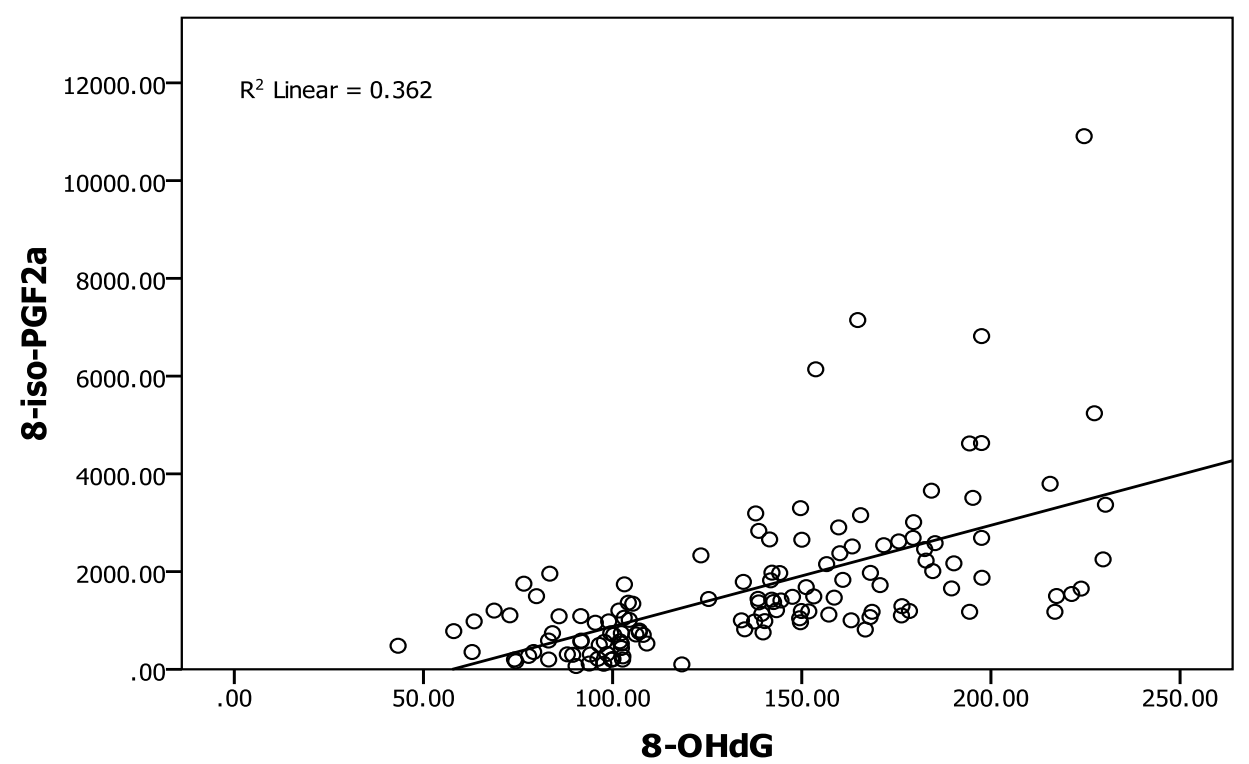

Figure 2. Correlation between 8-OHdG and 8-iso-PGF2 $\alpha$ in all participants $(\mathrm{r}=0.6, \mathrm{p}<0.0001)$.

\section{Discussion}

Diabetes is a major source of morbidity, mortality and economic cost to society [22]. Despite well-controlled blood glucose, diabetic complications still inevitably take place via several mechanisms including excessive generation of free radicals in patients who suffer from diabetes mellitus (DM) [7]. Therefore, this research article was conducted to study hyperglycemia and abnormal lipid profile in diabetic patients and its correlation with oxidative stress development as measured by 8-iso-PGF2 $\alpha$ and 8-OHdG.

The risk of developing type 2 diabetes increases with age, obesity, and lack of physical activity [23]. The age of diabetic patients in our study was observed to be $\geq 40 \mathrm{yrs}$ in $96 \%$ proving that age plays a significant role in the risk of developing type $2 \mathrm{DM}$ especially after 40 yrs [24]. However, it has been observed that insulin secretion declines with advancing age, and this decline may be accelerated by genetic factors [25].

Diabetes is a disease characterized by poor glycemic control [26]. Hyperglycemia generates reactive oxygen species (ROS), which in turn cause damage to the cells in many ways [27] [28]. OS can simultaneously result damage in biomolecules including lipids, proteins, nucleic acids and carbohydrates [29]. Lipids are reported as one of the primary targets of ROS [30]. Isoprostanes are a recently discovered group of prostaglandin isomers. Results of previous studies suggest that they can be used as oxidative stress markers, because in a number of cardiovascular, pulmonary and neurological diseases, their levels in biological samples considerably increase [31].

Jelinek et al. [32] demonstrated a significant increase in 8-iso-PGF2 $\alpha$ in the IFG group and supports the findings that, 8-iso-PGF2 $\alpha$ was increased following an oral glucose tolerance in individuals with no diabetes but with either IFG or impaired glucose tolerance [33]. 8-iso-PGF2 $\alpha$ was elevated in the sera of diabetic patients (2719.38 \pm $1864.68 \mathrm{pg} / \mathrm{ml}$ ) in current study compared with non-diabetic control (951.45 \pm 669.44 
$\mathrm{pg} / \mathrm{ml}, \mathrm{p}<0.0001)$. Similar results were recorded by Gopaul et al. [34], that, the plasma levels of 8-iso-PGF2 $\alpha$ in non-insulin dependent diabetes mellitus (NI-DDM, diabetes type 2) were higher $(\mathrm{N}=39,0.49-2.16 \mathrm{nM})$ than in the control group $(\mathrm{N}=16,0.02$ $0.63 \mathrm{nM}$ ) and by Davi et al. [35] in urine samples, that 8-iso-PGF2 $\alpha$ in patients with NID-DM $(419 \pm 208 \mathrm{pg} / \mathrm{mg}$ creatinine $)$ were significantly higher $(\mathrm{p}=0.0001)$ than in age-matched healthy subjects ( $208 \pm 92 \mathrm{pg} / \mathrm{mg}$ creatinine).

A clinical study performed by Bandeira and coworkers [36] aimed at characterizing blood oxidative stress in diabetic patients, reported a significant higher lipid peroxidation which showed a close relationship with high glucose levels as observed by the fasting glucose and HbAlc levels. This observation are in consistent with our findings in diabetic patients, that higher lipid peroxidation as measured by 8 -iso-PGF2 $\alpha$ showed a close relationship with FBG $(r=0.553, p<0.0001)$ and HbA1c $(r=0.6, p<0.0001)$. Therefore, increased lipid peroxidation presents a close relationship with the high glycemic levels and oxidative stress in diabetes mellitus [36] [37].

Changes in serum lipids have been demonstrated in the IFG stage and are associated with oxidation of arachidonic acid to 8-iso-PGF2 $\alpha$ [38] [39]. Changes in serum lipids was demonstrated in diabetic patients of our study and a significant association was recorded with 8-iso-PGF2 $\alpha$. Serum lipids showed significant elevation in diabetic patients $(\mathrm{p}<0.0001)$ but in HDL-C, a significant decrease $(\mathrm{p}=0.04)$ was recorded confirming other reports [32] demonstrated a significant reduction in both total cholesterol and HDL-C which explains the increased 8-iso-PGF2 $\alpha$ as HDL-C caries 8-iso-PGF2 $\alpha$ [10].

Like the oxidation of lipids and proteins, the oxidation of DNA reveals information on the overall state of the system being investigated. DNA oxidation is of particular concern for mitotic tissues, where increases in DNA mutations are believed to increase risk for cancer development [40]. Oxidized DNA as measured by 8-OHdG in our study was elevated significantly $(\mathrm{p}<0.0001)$ in diabetic patients compared with non-diabetic control referring to the risk in DNA oxidative damage and cancer development. Therefore, data collected by measurement of oxidized DNA bases in serum or excreted in urine, most notably 8-OHdG have served as a biomarker for carcinogenesis [41].

8-OHdG has been suggested to serve as a new sensitive biomarker of the in vivo oxidative DNA damage in diabetes [42]. In current study, 8-OHdG in diabetic patients was associated with hyperglycemia and abnormal serum lipids. LDL showed significant elevation in diabetic patients and the correlation with 8-OHdG was highly significant ( $\mathrm{r}$ $=0.28, \mathrm{p}=0.001)$ on contrary with other reports [43]. Lower HDL-C was detected in diabetic patients more frequently than in non-diabetic control $(\mathrm{p}=0.04)$ but negative correlation with 8-OHdG was detected insignificant consisting with the finding of Taskinen [44] and on contrary with the conclusion of Abdel-Aal et al. [45] that lower HDL-C showed significant negative correlation with 8-OHdG. Reduced HDL-C in diabetic subjects result from higher catabolic rate of HDL-C with normal activity of cholesterol ester transfer protein and hepatic lipase in insulin resistance conditions [45].

The good correlation between $8-\mathrm{OHdG}$ and isoprostanes in diabetic patients was well 
documented by Harman et al. [46] and in our report ( $\mathrm{r}=0.6, \mathrm{p}<0.0001)$. However, some researchers [47] reported the elevated levels of 8-OHdG and 8-iso-PGF2 $\alpha$ in the diabetics, although these studies have not shown the association between them. The association of 8-iso-PGF2 $\alpha$ and 8-OHdG with hyperglycemia (FBG and HBA1c), elevated LDL-C and triglycerides in diabetic patients of our study was confirmed by other studies [43] [48] reflecting a generalized cellular oxidative stress which may be a risk factor for diabetic complication and cancer development as suggested by Brownlee [49] that hyperglycemia-induced overproduction of superoxide, plays a critical role in the biochemical abnormalities leading to vascular disease and diabetic complications. Therefore, serum 8-OHdG and 8-iso-PGF2 $\alpha$ could be used for early prediction of diabetic complications and cancer development as urinary 8-OHdG and 8-iso-PGF2 $\alpha$ excretions have been measured in many studies because they are associated with cancer development and advancement of diabetes and atherosclerosis [50].

\section{Conclusion}

Diabetic patient's type 2 has a higher rate of abnormal lipid profile and correlates significantly with oxidative stress as measured by 8 -iso-PGF2 $\alpha$ and 8 -OHdG. Therefore, 8 -iso-PGF $2 \alpha$ and 8 -OHdG could be used as oxidative biomarkers for evaluating diabetic patients with early prediction for its complications and cancer development.

\section{Acknowledgements}

This research project was supported and funded by the Institute of Scientific Research and Revival of Islamic Culture (Grant No. 43409027), Umm Al-Qura University, Makkah, KSA.

\section{Authors' Contributions}

All authors equally contributed in the article. All authors read and approved the final manuscript.

\section{Conflict of Interests}

The authors declare that they have no competing interests regarding the publication of this manuscript.

\section{Declarations}

- Ethics approval and consent to participate: The study protocol was approved by Ethics Review Board for Human Studies at Faculty of Medicine, Umm Al-Qura University and conformed to the ethical guidelines of the 1975 Helsinki declaration.

- Availability of data and material: The dataset(s) supporting the conclusions of this article is (are) included within the article and its additional files.

- Funding: Funded by the Institute of Scientific Research and Revival of Islamic Culture (Grant No. 43409027), Umm Al-Qura University, Makkah, KSA. 


\section{Limitations}

- Although this is an attempt to study oxidative biomarkers that might be of significance in progression of diabetic patients, only a limited number of cases were investigated here.

- Since the prognosis of diabetes type 2 remains poor and identification of useful molecular prognostic markers for diabetic complications is required, follow up of diabetic patients must be studied in further study.

- Other risk factors like obesity might be of significance in the progression of diabetic complications and must be studied in further study.

\section{References}

[1] American Diabetes Association (2013) Diagnosis and Classification of Diabetes Mellitus. Diabetes Care, 35, S64-S71. https://doi.org/10.2337/dc13-s067

[2] Krauss, R.M. (2004) Lipids and Lipoproteins in Patients with Type 2 Diabetes. American Diabetes Association. Diabetes Care, 27, 1496-1504.

https://doi.org/10.2337/diacare.27.6.1496

[3] Garvey, W.T., Kwon, S., Zheng, D., Shaughnesy, S., Wallace, P., Hutto, A., et al. (2003) Effects of Insulin Resistance and Type 2 Diabetes on Lipoprotein Subclass Particle Size and Concentration Determined by Nuclear Magnetic Resonance. Diabetes, 52, 453-462. https://doi.org/10.2337/diabetes.52.2.453

[4] Reaven, G.M., Chen, Y.D., Jeppesen, J., Maheux, P. and Krauss, R.M. (1993) Insulin Resistance and Hyperinsulinemia in Individuals with Small Dense Low Density Lipoprotein Particles. Journal of Clinical Investigation, 92, 141-146. https://doi.org/10.1172/JCI116541

[5] Bagherzadeh, F., Ebrahimi-Mameghani, M., Jafarabadi, M.A., Aslani, Z. and Edalati, S. (2015) Evaluation of Oxidative DNA Damage and Its Relation with Anthropometric Indices in Healthy Adolescents. International Journal of Nutrition and Food Sciences, 3, 21-25.

[6] Jang-Young, K., Jun-Won, L., YounMin-Soo, A. and Sung-Gyun, A. (2012) Urinary Levels of 8-Iso-Prostaglandin F2 $\alpha$ and Hydroxyl Deoxyguanosin as Markers of Oxidative Stress in Patients with Coronary Artery Disease. Korean Circulation Journal, 42, 614-617. https://doi.org/10.4070/kcj.2012.42.9.614

[7] Porasuphatana, S., Suddee, S., Nartnampong, A., Konsil, J., Harnwong, B. and Santaweesuk, A. (2012) Glycemic and Oxidative Status of Patients with Type 2 Diabetes Mellitus Following Oral Administration of Alpha-Lipoic Acid: A Randomized Double-Blinded PlaceboControlled Study. Asia Pacific Journal of Clinical Nutrition, 21, 12-21.

[8] Evans, M.D., Dizdaroglu, M. and Cooke, M.S. (2004) Oxidative DNA Damage and Disease: Induction, Repair and Significance. Mutation Research/Reviews in Mutation Research, 567, 1-61. https://doi.org/10.1016/j.mrrev.2003.11.001

[9] Guichardant, M., Bacot, S., Moliere, P. and Lagarde, M. (2006) Hydroxy-Alkenals from the Peroxidation of n-3 and n-6 Fatty Acids and Urinary Metabolites. Prostaglandins, Leukotrienes and Essential Fatty Acids, 75, 179-182. https://doi.org/10.1016/j.plefa.2006.05.006

[10] Proudfoot, J.M., Barden, A.E., Loke, W.M., Croft, K.D., Puddey, I.B. and Mori, T.A. (2009) HDL Is the Major Lipoprotein Carrier of Plasma F2-Isoprostanes. Journal of Lipid Research, 50, 716-722. https://doi.org/10.1194/jlr.M800607-JLR200

[11] Chang, C.M., Hsieh, C.J., Huang, J.C. and Huang, I.C. (2012) Acute and Chronic Fluctuations in Blood Glucose Levels Can Increase Oxidative Stress in Type 2 Diabetes Mellitus. 
Acta Diabetologica, 49, 171-177. https://doi.org/10.1007/s00592-012-0398-x

[12] Niedowicz, D.M. and Daleke, D.L. (2005) The Role of Oxidative Stress in Diabetic Complications. Cell Biochemistry and Biophysics, 43, 289-330.

https://doi.org/10.1385/CBB:43:2:289

[13] Roberts, L.J. and Morrow, J.D. (2002) Products of the Isoprostane Pathway: Unique Bioactive Compounds and Markers of Lipid Peroxidation. Cellular and Molecular Life Sciences, 59, 808-820. https://doi.org/10.1007/s00018-002-8469-8

[14] Kaviarasan, S., Muniandy, S., Qvist, R., Chinna, K. and Ismail, I.S. (2010) Is F2-Isoprostane a Biological Marker for the Early Onset of Type 2 Diabetes Mellitus? International Journal of Diabetes in Developing Countries, 30, 167-170. https://doi.org/10.4103/0973-3930.66514

[15] Il'yasova, D., Spasojevic, I., Base, K., Zhang, H., Wang, F., Young, S.P., et al. (2012) Urinary F2-Isoprostanes as a Biomarker of Reduced Risk of Type 2 Diabetes. Diabetes Care, 35, 173-174. https://doi.org/10.2337/dc11-1502

[16] Committee Report (1997) Report of the Expert Committee on the Diagnosis and Classification of Diabetes Mellitus. Diabetes Care, 20, 1183-1197.

https://doi.org/10.2337/diacare.20.7.1183

[17] Friedewald, W., Levy, R. and Frederickson, S. (1972) Estimation of the Concentration of Low-Density Lipoprotein Cholesterol in Plasma, without Use of the Preparative Ultracentrifugation. Clinical Chemistry, 18, 499-502.

[18] Castelli, W.P., Abbott, R.D. and McNamara, P.M. (1983) Summary Estimates of Cholesterol Used to Predict Coronary Heart Disease. Circulation, 67, 730-734.

https://doi.org/10.1161/01.CIR.67.4.730

[19] Third Report of the National Cholesterol Education Program (NCEP) (2002) Expert Panel on Detection, Evaluation, and Treatment of High Blood Cholesterol in Adults (Adult Treatment Panel III) Final Report. Circulation, 106, 3143-3421.

[20] The Diabetes Control and Complications Trial (2005) Intensive Diabetes Treatment and Cardiovascular Disease in Patients with Type 1 Diabetes. New England Journal of Medicine, 353, 2643-2653. https://doi.org/10.1056/NEJMoa052187

[21] Chard, T. (1990) An Introduction to Radioimmunoassay \& Related Techniques. 4th Edition, Elsevier, Amesterdam.

[22] Tiwari, B.K., Pandey, K.B., Abidi, A.B. and Rizvi, S.I. (2013) Markers of Oxidative Stress during Diabetes Mellitus. Journal of Biomarkers, 2013, Article ID: 378790. https://doi.org/10.1155/2013/378790

[23] American Diabetes Association (2013) Diagnosis and Classification of Diabetes Mellitus. Diabetes Care, 36, S67-S74. https://doi.org/10.2337/dc13-s067

[24] Tagoe, D.N.A. and Amo-Kodieh, P. (2013) Type 2 Diabetes Mellitus Influences Lipid Profile of Diabetic patients. Annals of Biological Research, 4, 88-92.

[25] Mezzetti, A., Cipollone, F. and Cuccurullo, F. (2000) Oxidative Stress and Cardiovascular Complications in Diabetes: Isoprostanes as New Markers on an Old Paradigm. Cardiovascular Research, 47, 475-488. https://doi.org/10.1016/S0008-6363(00)00118-8

[26] Pazdro, R. and Burgess, J.R. (2010) The Role of Vitamin E and Oxidative Stress in Diabetes Complications. Mechanisms of Ageing and Development, 131, 276-286.

https://doi.org/10.1016/j.mad.2010.03.005

[27] Hunt, J.V., Dean, R.T. and Wolff, S.P. (1988) Hydroxyl Radical Production and Autoxidative Glycosylation. Glucose Autoxidantion as the Cause of Protein Damage in the Experimental Glycation Model of Diabetes Mellitus and Ageing. Biochemical Journal, 256, 205- 
212. https://doi.org/10.1042/bj2560205

[28] Jaganjac, M., Tirosh, O., Cohen, G., Sasson, S. and Zarkovic, N. (2013) Reactive AldehydesSecond Messengers of Free Radicals in Diabetes Mellitus. Free Radical Research, 47, 39-48. https://doi.org/10.3109/10715762.2013.789136

[29] Granot, E. and Kohen, R. (2004) Oxidative Stress in Childhood-In Health and Disease States. Clinical Nutrition, 23, 3-11. https://doi.org/10.1016/S0261-5614(03)00097-9

[30] Halliwell, B. and Chirico, S. (1993) Lipid Peroxidation: Its Mechanism, Measurement and Significance. American Journal of Clinical Nutrition, 57, 715S-724S.

[31] Czerska, M., Zieliński, M. and Gromadzińska, J. (2016) Isoprostanes-A Novel Major Group of Oxidative Stress Markers. International Journal of Occupational Medicine and Environmental Health, 29, 179-190.

[32] Jelinek, H.F., Jamil, D.A. and Al-Aubaidy, H.A. (2014) Impaired Fasting Glucose \& 8-Iso-Prostaglandin F2 $\alpha$ in Diabetes Disease Progression. British Journal of Medicine \& Research, 4, 5229-5237. https://doi.org/10.9734/BJMMR/2014/11147

[33] Gopaul, N.K., Manraj, M.D., Hebe, A., Lee, K., Yan, S., Johnston, A., et al. (2001) Oxidative Stress Could Precede Endothelial Dysfunction and Insulin Resistance in Indian Mauritians with Impaired Glucose Metabolism. Diabetologia, 44, 706-712. https://doi.org/10.1007/s001250051679

[34] Gopaul, N.K., Anggård, E.E., Mallet, A.I., Betteridge, D.J., Wolff, S.P. and Nourooz-Zadeh, J. (1995) Plasma 8-Epi-PGF2 Alpha Levels Are Elevated in Individuals with Non-Insulin Dependent Diabetes Mellitus. FEBS Letters, 368, 225-229. https://doi.org/10.1016/0014-5793(95)00649-T

[35] Davi, G., Ciabattoni, G., Consoli, A., Mezzetti, A., Falco, A., Santarone, S., et al. (1999) In Vivo formation of 8-Iso-Prostaglandin F2 $\alpha$ and Platelet Activation in Diabetes Mellitus: Effect of Improved Metabolic Control and Vitamin E Supplementation. Circulation, 99, 224-229. https://doi.org/10.1161/01.CIR.99.2.224

[36] Bandeira, S.M., Guedes, G.S., Fonseca, L.J.S., Pires, A.S., Gelain, D.P. and Moreira, J.C. (2012) Characterization of Blood Oxidative Stress in Type 2 Diabetes Mellitus Patients: Increase in Lipid Peroxidation and SOD Activity. Oxidative Medicine and Cellular Longevity, 2012, Article ID: 819310. https://doi.org/10.1155/2012/819310

[37] Salgueiro, A.C., Leal, C.Q., Bianchini, M.C., Prado, I.O., Mendez, A.S., Puntel, R.L., et al. (2013) The Influence of Bauhinia forficate Link Sub sp. Pruinosa Tea on Lipid Peroxidationand Non-Protein SH Groups in Human Erythrocytes Exposed to High Glucose Concentrations. Journal of Ethnopharmacology, 148, 81-87. https://doi.org/10.1016/j.jep.2013.03.070

[38] Poli, G., Leonarduzzi, G., Biasi, F. and Chiarpotto, E. (2004) Oxidative Stress and Cell Signaling. Current Medicinal Chemistry, 11, 1163-1182. https://doi.org/10.2174/0929867043365323

[39] Meikle, P.J., Wong, G., Barlow, C.K., Weir, J.M., Greeve, M.A., Maclntosh, G.L., et al. (2013) Plasma Lipid Profiling Shows Similar Associations with Prediabetes and Type 2 Diabetes. PLoS ONE, 8, e74341. https://doi.org/10.1371/journal.pone.0074341

[40] Halliwell, B. (2002) Effect of Diet on Cancer Development: Is Oxidative DNA Damage a Biomarker? Free Radical Biology and Medicine, 32, 968-974. https://doi.org/10.1016/S0891-5849(02)00808-0

[41] Valavanidis, A., Vlachogianni, T. and Fiotakis, C. (2009) 8-Hydroxy-2'-Deoxyguanosine (8-OHdG): A Critical Biomarker of Oxidative Stress and Carcinogenesis. Journal of Environmental Science and Health Part C, 27, 120-139. 
https://doi.org/10.1080/10590500902885684

[42] Kanuchi, M., Nishioka, H. and Hashimoto, T. (2002) Oxidative DNA Damage and Tubulointerstitial Injury in Diabetic Nephropathy. Nephron, 91, 327-329.

https://doi.org/10.1159/000058412

[43] Al-Aubaidy, H.A. and Jelinek, H.F. (2011) Oxidative DNA Damage: Antioxidant Response in Postprandial Hyperglycemia in Type 2 Diabetes Mellitus. The British Journal of Diabetes \& Vascular Disease, 11, 87-91. https://doi.org/10.1177/1474651411405259

[44] Taskinen, M. (2003) Diabetic Dyslipidemia: From Basic Research to Clinical Practice. Diabetologia, 46, 733-749. https://doi.org/10.1007/s00125-003-1111-y

[45] Abdel-Aal, N., Ahmad, A., Froelicher, E., Baticha, A., Hamza, M. and Ajiouni, K. (2008) Prevalence of Dyslipidemia in Patients with Type 2 Diabetes in Jordan. Saudi Medical Journal, 29, 1423-1428.

[46] Harman, S.M., Liang, L., Tsitouras, P.D., Gucciardo, F., Heward, C.B., Reaven, P.D., et al. (2003) Urinary Excretion of Three Nucleic Acid Oxidation Adducts and Isoprostane F2 Alpha Measured by Liquid Chromatography Mass Spectrometry in Smokers, Ex-Smokers and Nonsmokers. Free Radical Biology and Medicine, 35, 1301-1309. https://doi.org/10.1016/j.freeradbiomed.2003.07.003

[47] Nakanishi, S., Suzuki, G., Kusunoki, Y., Yamane, K., Egusa, G. and Kohno, N. (2004) Increasing of Oxidative Stress from Mitochondria in Type 2 Diabetic Patients. Diabetes/Metabolism Research and Reviews, 20, 399-404. https://doi.org/10.1002/dmrr.469

[48] Ceriello, A., Esposito, K., Piconi, L., Ihnat, M., Thorpe, J., Testa, R., et al. (2008) Glucose "Peak" and Glucose "Spike". Impact on Endothelial Function and Oxidative Stress. Diabetes Research and Clinical Practice, 82, 262-267.

https://doi.org/10.1016/j.diabres.2008.07.015

[49] Brownlee, M. (2001) Biochemistry and Molecular Cell Biology of Diabetic Complications. Nature, 414, 813-820. https://doi.org/10.1038/414813a

[50] Sakano, N., Wang, D.-H., Takahashi, N., Wang, B., Sauriasari, R., Kanbara, S., et al. (2009) Oxidative Stress Biomarkers and Lifestyles in Japanese Healthy People. Journal of Clinical Biochemistry and Nutrition, 44, 185-195. https://doi.org/10.3164/jcbn.08-252 


\section{Abbreviation Note List}

DM type 2: Diabetes mellitus type 2

FBG: Fasting blood glucose

PBS: Postprandial blood glucose

HbAlc: hemoglobinalc

HDL-C: High density lipoprotein-cholesterol

LDL-C: Low density lipoprotein-cholesterol

VLDL: Very low density lipoprotein

TG: Triglycerides

TC: Total cholesterol

DNA: Deoxyribonucleic acid

8-iso-PGF2 $\alpha$ : 8 -iso-prostaglandin F2 $\alpha$

8-OHdG: 8-hydroxy deoxyguanosin

ROS: Reactive oxygen species

HRP: Horse radish peroxidase

DCCT: Diabetic control and complications trial

ELISA: Enzyme linked immunosorbent assay

IFG: Impaired Fasting glucose

NI-DDM diabetes type 2: Non insulin-dependent diabetes mellitus type 2

Submit or recommend next manuscript to SCIRP and we will provide best service for you:

Accepting pre-submission inquiries through Email, Facebook, LinkedIn, Twitter, etc.

A wide selection of journals (inclusive of 9 subjects, more than 200 journals)

Providing 24-hour high-quality service

User-friendly online submission system

Fair and swift peer-review system

Efficient typesetting and proofreading procedure

Display of the result of downloads and visits, as well as the number of cited articles

Maximum dissemination of your research work

Submit your manuscript at: http://papersubmission.scirp.org/

Or contact jdm@scirp.org 